\title{
Electric Boat Propulsion System Using Multilevel Converter Based on ANN Controller
}

\author{
K. Selvakumar, Siddharth S Menon, K Varun Kaushik, D. Karthikeyan
}

\begin{abstract}
In this system, we use a Multi-level inverter to power an electric boat propulsion system powered by PV Panels. The eleven-level inverter is used to supply power to multi-level switching cells of the inverter which drives the AC motor.It is an Asymmetrical Cascaded H-bridge Inverter. A Multi Carrier PWM signal is given based on Multi Carrier Modulation Technique to obtain equal steps in the eleven-level output. A Sepic converter is used which allows adjustment of a range of $D C$ voltages to provide a constant voltage output. It is a DC converter that basically regulates the voltage from the $P V$ Panel and all subtractive and additive combinations of DC input levels can be obtained in the output signal. ANN controller is applied forming an efficient closed loop system that is involved in the elimination of harmonics in PWM inverters.It reduces the overall Total Harmonic distortion. The system consists of optimized PI based MPPT that ensures efficient $P V$ power generation.
\end{abstract}

Keywords: PWM-Pulse width Modulation, ANN -Artificial Neural Network, MPPT -Maximum Power Point Technique

\section{INTRODUCTION}

Global market is moving towards vehicles that are electrically powered. They are being given more importance everywhere in the world. Developing electric vehicles is important in reducing greenhouse gas $(\mathrm{GHG})$ emissions. The wide - ranging implementation of electrically powered vehicles offer significant improvements to society, not only in terms of technology that we use for personal transport, as well as in pushing our economies away from petroleum and learning about the ecological footprint of transport.

Due to their reduced electromagnetic interfaces (EMI), reduced switching frequency, increased high voltage rating and reduced switching losses than conventional two - level inverters, multi-level power conversion has been highly recognized for increased power and voltage applications. Multi-level inverter output voltage signal is made and characterized by multiple DC voltage sources and it performs as a type of amplitude modulation, making the inverter outputs much cleaner. In recent literatures, innumerable topologies and many strategies have been introduced for modulation and are extensively pursued for useful and driving applications.

$\mathrm{H}$ - bridges that are connected in series are exceptionally preferred in the multi-level inverter family due to their

Revised Version Manuscript Received on 10, September 2019.

K. Selvakumar, Assistant Professor, Department of EEE, SRM IST, Chennai - 603203, Tamil Nadu, India.

Siddharth S Menon, UG Research Scholar, Department of EEE, SRM IST, Chennai - 603203, Tamil Nadu, India.

K Varun Kaushik, UG Research Scholar, Department of EEE, SRM IST, Chennai - 603203, Tamil Nadu, India.

D.Karthikeyan, Assistant Professor, Department of EEE, SRM IST, Chennai - 603203, Tamil Nadu, India. modularity and control simplicity. In addition, many modulation methods such as Sinusoidal PWM(SPWM),Non Sinusoidal PWM, Selective Harmonic Elimination (SHE) and Space Vector PWM(SVPWM) were considered for multi-level inverters to reduce unwanted harmonic signals and regulate the voltage output of the inverter. Only the Selective Harmonic Eliminated (SHE) method can completely eliminate low-order harmonics among the mentioned techniques.Iterative methods based on mathematical techniques or resultant theory can be applied in the SHE method to measure the desired angles for switching so as to eliminate lower order dominant harmonics. In power electronics and electric drive application areas, the application of artificial neural networks (ANNs) has recently grown. ANNs application is for the DC motor drives for the control of $\mathrm{DC}$ to $\mathrm{AC}$ inverters in the current control of inverters. In the literature, use of ANNs has been presented for the elimination of harmonics in PWM inverters, where the Artificial Neural Network changes a high - memory demanding lookup table to make a PWM inverter's switching angles for an existing modulation index.

The system is used to control the speed and increase the efficiency and for this purpose the inverter is used. Commonly used inverter is VSI (Voltage source inverter) with three level outputusing switches $\mathrm{H} 1$ and $\mathrm{H} 2$ (positive cycle 180 degrees), $\mathrm{H} 3$ and $\mathrm{H} 4$ (negative cycle 180 degrees). $\mathrm{H} 1$ and $\mathrm{H} 3$ is present in same leg while $\mathrm{H} 2$ and $\mathrm{H} 4$ in the other leg of the inverter. Total output forms 360 degrees. Thus it follows 180 degree mode of operation. When $300 \mathrm{~V}$ is given to the inverter, there will be an output of $230 \mathrm{~V}$ AC. Thus, there is a voltage drop of $70 \mathrm{~V}$. In order to reduce this drop, the Total Harmonic Distortion (THD) must be calculated

For $330 \mathrm{~V}$ drop is $70 \mathrm{~V}$.

For $100 \mathrm{~V}$ drop is $70 \times 100 / 330=23.33 \mathrm{~V}$.

Therefore, losses percentage is $23.33 \%$, which needs to be reduced. Hence, multilevel inverter is used.

Multilevel inverter is the generation of high voltage using lower voltage rating devices connected in series. MOSFET or IGBT are used for switches but only in series. In parallel, it will work as the load. Multilevel signal can be obtained by cascading $\mathrm{H}$ bridge inverters. Five levelsignal is obtained by cascading three inverters.For 11 level, we use the formula

M - $(1 / 2)$ 


\section{ELECTRIC BOAT PROPULSION SYSTEM USING MULTILEVEL CONVERTER BASED ON ANN CONTROLLER}

where $\mathrm{M}$ is the number of levels required.

Here after calculating, approximately five inverters are required. So we have to connect five inverters in series to get eleven level. Each inverter has 4 switches, so total number of switches required is $4 \times 5=20$ switches. Thus the two main objective of the project is to reduce the THD and to reduce number of switches, and to do this, an asymmetrical cascaded $\mathrm{H}$-Bridge inverter is used.

For power electronics devices, an artificial neural network application which is new is implemented in which it is applied like an alternative to the lookup table for switching angles to produce the ideal angles for switching for a multi-level inverter. The benefits of this technique is quick setup and simple circuit, constantly regulating the scale of the output voltage versus modulation indices, and after training the ANN there is no need for a lookup table. Even so, there is no assurance of estimating the best solution of performance of the probable combination of these over a specified modulation index by the proposed system in estimating the optimum switching angles.

On the inverter side, multi-carrier modulation is applied as PWM and applied to the closed loop system of ANN. For increased performance and efficiency, ANN Controller helps lower harmonic losses in PWM Inverters. The goal is to create a fully electrical propulsion system for an increased range boat powered by photovoltaic panels. For an electric boat application, we use an eleven-level $\mathrm{H}$ Bridge Inverter to increase efficiency. Modulation control of an eleven level multi-level inverter is quite difficult, but with the help of Multicarrier PWM Technique in the closed loop system, proper output with equal steps is achieved.

\section{ELECTRIC PROPULSION SYSTEM}

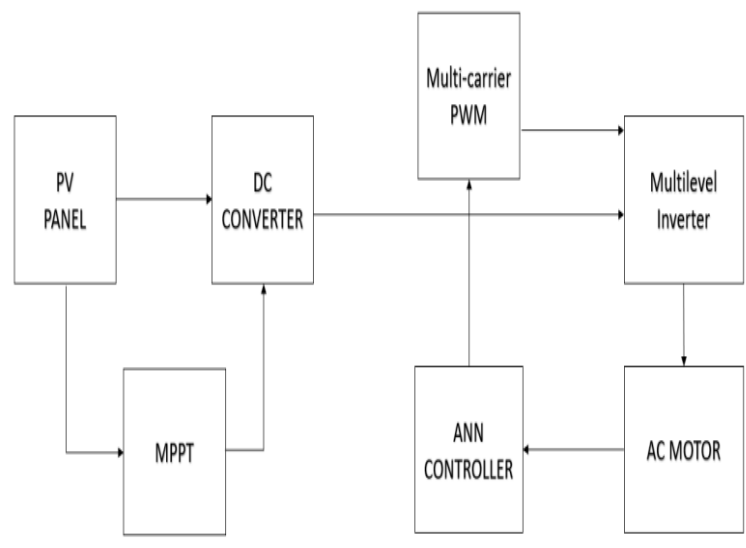

Fig.1.Block Diagram

In the auxiliary circuit, a split-phase motor has no capacity. It uses conductors that are narrow to obtain a high ratio of reaction resistance, a phase shift is achieved with respect to that of the main current. Increasing the resistance means that the auxiliary winding can be used only when starting, otherwise it will overheat. The auxiliary winding will heat up as the resistance in increased.Therefore it can be only used during starting.

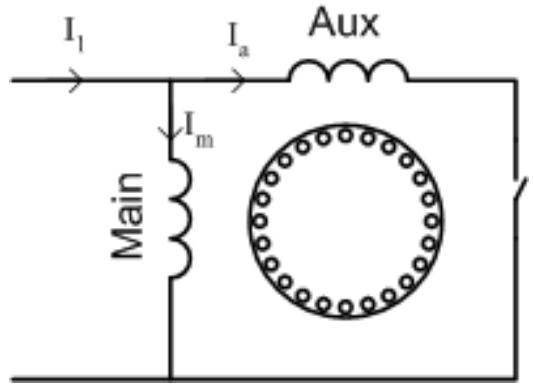

Fig.2.Split phase IM

Split Phase IM is preferred over general capacitor motors because they have very low torque.

An induction motor generally runs on a speed less than the synchronous speed which is why it called as an asynchronous motor. The rotor speed never equals to the synchronous speed due to a factor called $\operatorname{slip}(\mathrm{s})=$ stator field $\operatorname{speed}(\mathrm{N}) \mathrm{s}-$ rotor speed(N)r.

The drive system consists of Sepic converter-H bridge Inverter topology which is connected with multiplier cells between them. The DC voltage from the PV panels is received by the sepic converter. In the system Four PV panels are used and hence four sepic converters are present. The signal is multiplied at the multiplier cells and then it is converted to AC Eleven level Voltage output with the help of the H-Bridge Inverter.The drive system is called Asymmetrical Cascaded $\mathrm{H}$ bridge inverter.

\section{III.POWER CONVERTERS OF DRIVE SYSTEM}

SEPIC - Single Ended Primary Inducer Converter is a converter that does DC TO DC conversion and allows output voltage of the converter to be less than, greater than, or same as that of the input. The SEPIC output is regulated by the control transistor's duty cycle.

It is basically a combination of boost converter and a buck boost converter, thus it closely resembles a conventional buck boost converter, but is more efficient due to non inverted output (voltage polarity of input and output are the same), energy is coupled from input to output when a series condenser is applied (thus will be able to react more graciously to a small circuit output signal), and being able to come to a proper stop: The output drops to $0 \mathrm{~V}$ after relatively heavy transient load dump when the switch is in OFF position

SEPIC converter has lots of advantages compared to other DC to DC converters. It has high gain. It can boost the voltage uptoeight times, due to the diode present in the circuit, it will act as the dv/dt protection circuit or the snubber circuit. Due to two inductors and two capacitor present, it will work as the second order low pass filter. Thus it is also known as the double frequency suppressant. The output ripple is also reduced twice as much as the normal output.

Application of SEPIC is involved where the voltage of a battery may be over or underneath the desired output of the regulator. 
H-BRIDGE INVERTER

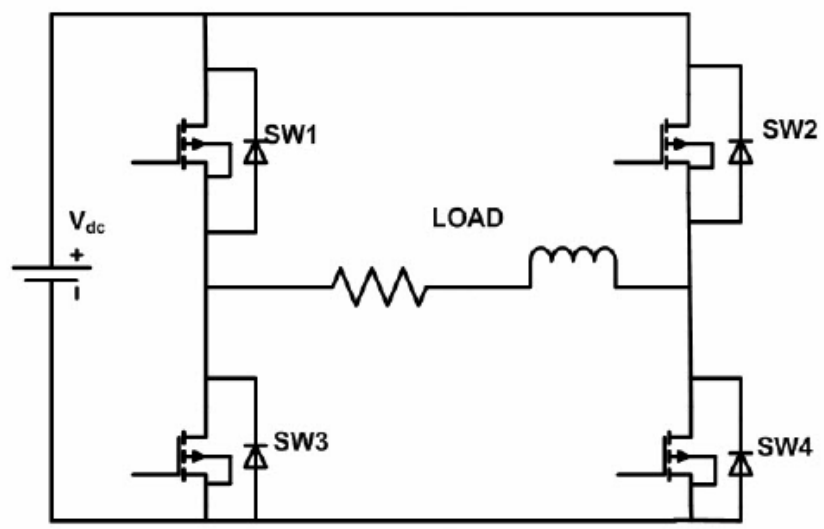

Fig.3.H Bridge Inverter

The term $\mathrm{H}$ bridge is derived from the circuit which is represented as an $\mathrm{H}$ shape graphically. For the construction of an $\mathrm{H}$ bridge, four switches, solid state or mechanical, can be used. The four switches are named as S1, S2, S3 and S4. When switches S1 and S4 (in reference to Fig.3) are closed and switch S2 and switch S3 are kept open, the voltage which is applied throughout the motor will be positive. When switches S1 and S4 are kept open and S2 and S3 switches are kept closed, the voltage is reversed thereby reversing the engine. The $\mathrm{H}$ bridge framework is typically applied in inverting the motor's direction/polarity. It can be also used to stop the motor suddenly as the terminals of the motor are shorted and ' brake' the motor, or to effectively disconnect the motor from the circuit and allow the motor to 'free run' to a halt. Asymmetrial cascaded 11 level inverter has $4 \mathrm{DC}$ sources, 4 switches, 4 diodes, $1 \mathrm{H}$-Bridge inverter.

\section{III.PRINCIPLE OF OPERATION}

The main components used in the hardware is two drive circuits, two transformers, level generator, inverter circuit and dsPIC microcontroller. A crystal oscillator is used for Pulse width modulation. While all the components are fed 12 $\mathrm{V}$, the dsPIC circuit is fed $5 \mathrm{~V}$. This is done by using a voltage regulator. The normal AC voltage is stepped down to 12 volts using the transformers and the fed to the level generator. The transformer is also used for creating different levels. The level generator consists of switch which is MOSFETs, with bridge rectifier and capacitors for each switch followed by a driver IC chip. A driver circuit which is usually based on transistors is used to amplify the current to the levels that are required to control small devices that use DC. The transistor performs like a increasing-current switch regulated by the digital logic lower current signal when the range of the current and voltage levels are perfect. The dsPIC is further used to completely remove any harmonics or other losses in the amplified signal. The proper signal is now sent to the eleven-level inverter that invert the DC supply to AC and gives Eleven level output. It is filtered to form sinusoidal signal to power the motor.

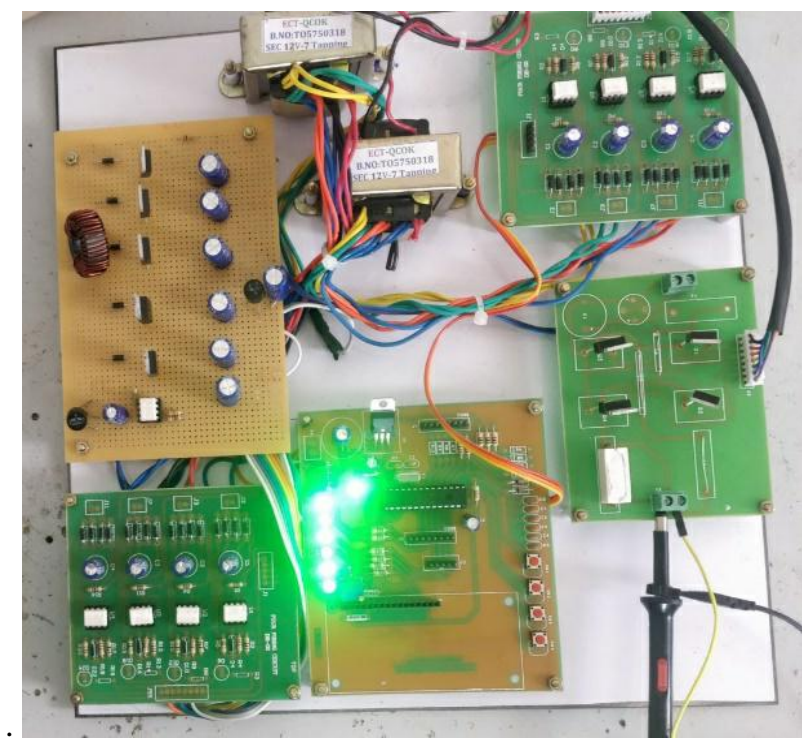

Fig.4.Hardware experimental setup

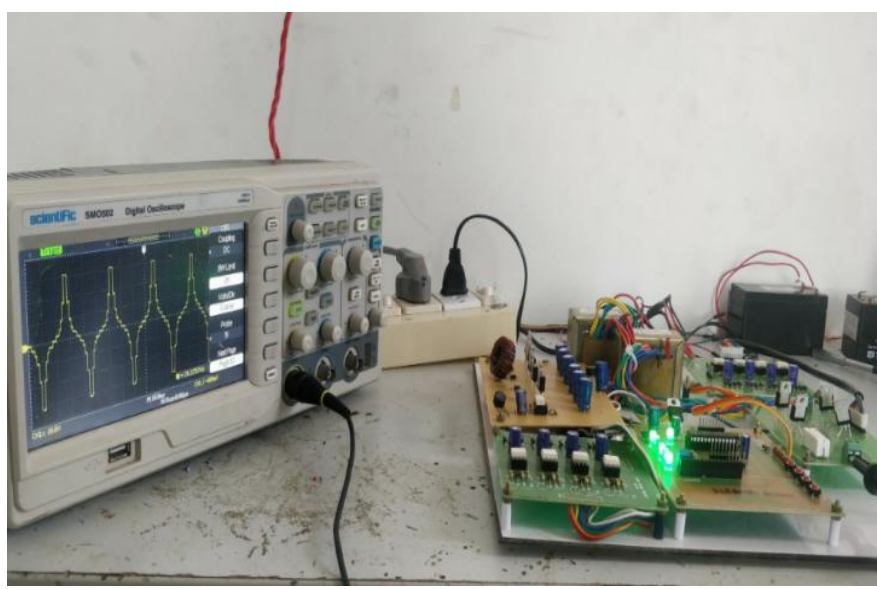

Fig.5.Operation of the Hardware system connected to the DSO.

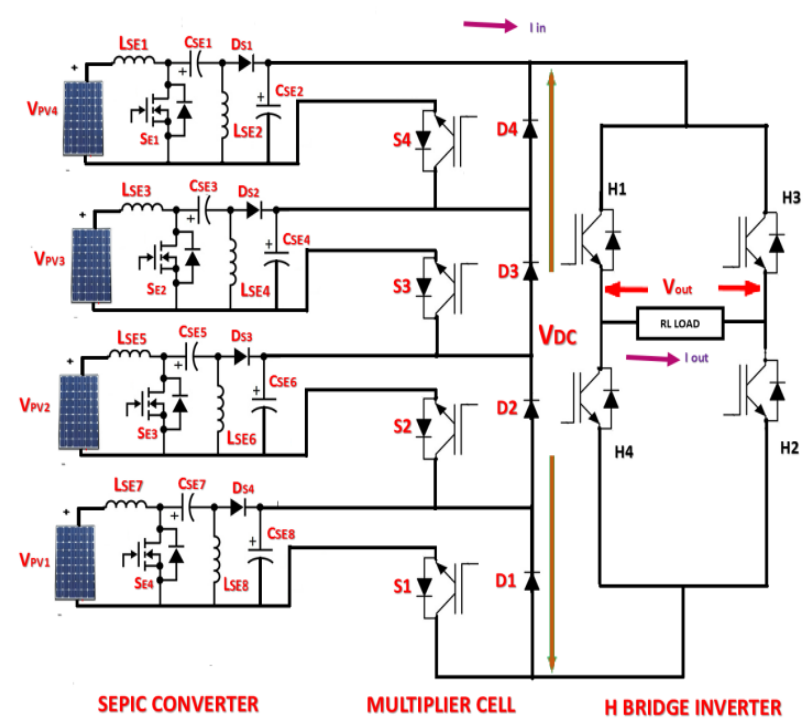

Fig.6.Circuit Diagram OF Multi Level Inverter 


\section{ELECTRIC BOAT PROPULSION SYSTEM USING MULTILEVEL CONVERTER BASED ON ANN CONTROLLER}

Power source of the system is solar energy which is absorbed by PV panels. MPPT used here is optimized PI. PI-MPPT increases efficiency. The solar PV module power is first fed to the SEPIC converter. The PI-MPPT controller controls the SEPIC converter to track the PV module's maximum power. To maintain maximum power profile throughout its output, the PI-MPPT controller generates pulses to control the operation of the SEPIC converter. This maximum power generated by photovoltaic cells is then supplied to the auxiliary circuit. The auxiliary circuit provides the required DC levels which are then inverted by the $\mathrm{H}$-Bridge inverter to deliver the eleven-level stair-case wave output that is converted into a sinusoidal waveform using a filter required to drive any load efficiently. The PWM control provides the auxiliary circuit switching sequence and the H-Bridge inverter. The control algorithm PI-MPPT and the control sequence PWM provide the overall system with satisfactory and efficient control.

\begin{tabular}{|l|l|l|l|}
\hline S4 & S3 & S2 & S1 \\
\hline 0 & 0 & 0 & 1 \\
\hline 0 & 0 & 1 & 0 \\
\hline 0 & 0 & 1 & 1 \\
\hline 0 & 1 & 0 & 0 \\
\hline 0 & 1 & 0 & 1 \\
\hline
\end{tabular}

\section{Table.1.Switching Mode of Electric drive system}

The working of the drive system is as follows: Let us assume that $6 \mathrm{~V}$ is given to the $1^{\text {st }}$ switch, $12 \mathrm{~V}$ in $2^{\text {nd }}$ switch, $24 \mathrm{~V}$ in the $3^{\text {rd }}$ and $48 \mathrm{~V}$ in the $4^{\text {th }}$. For positive cycle $\mathrm{H} 1$ and $\mathrm{H} 2$ are turned on. First only $\mathrm{S} 1$ for $1^{\text {st }}$ level is turned on, hence the $6 \mathrm{~V}$ DC is converted to AC. Next, only S2 for $2^{\text {nd }}$ level is turned on which is $12 \mathrm{~V}$. For $3^{\text {rd }}$ level, both $\mathrm{S} 1$ and $\mathrm{S} 2$ is turned on, hence $18 \mathrm{~V}$ is converted. For $4^{\text {th }}$ level $\left(\begin{array}{llll}0 & 1 & 0 & 0\end{array}\right)$, $\mathrm{S} 3$ is turned on which is $24 \mathrm{~V}$. For $5^{\text {th }}$ level, $\left(\begin{array}{llll}0 & 1 & 0 & 1\end{array}\right) \mathrm{S} 3$ and S1 is turned on which is $30 \mathrm{~V}$.Similarly, for the negative cycle, $\mathrm{H} 3$ and $\mathrm{H} 4$ switches are turned on. Upto 31 levels can be obtained by this technique using just 8 switches.In this experiment we use only 8 switches to obtain eleven level output whereas normal cascaded eleven level inverter require 20 switches. When S1 is used, S2 S3 S4 are in off condition. But since the circuit has to be closed, after S1 diodes D1, D2, D3 and D4 will conduct.

For PV system, from PV Panel less voltage is obtained, but for the input the requirement is more than $230 \mathrm{~V}$. Hence, instead of giving $6 \mathrm{~V}, 12 \mathrm{~V}, 24 \mathrm{~V}$ and $48 \mathrm{~V}, 33 \mathrm{~V}, 66 \mathrm{~V}, 132 \mathrm{Vetc}$ will be given. Here, a SEPIC DC-DC Converter is used.It has high gain and boosts the voltage up to eight times. Due to the diode present in the circuit, it will act as the dv/dt protection circuit or the snubber circuit.Due to two inductors and two capacitor present, it will work as the second order low pass filter.Hence called the double frequency suppressant, and output ripple will be reduced twice as much as the normal output.

\section{MULTI-CARRIER PWM TECHNIQUE}

The Multi-carrier PWM technique has been introduced to generate the PWM switching signals using several triangular carrier signals and only one modulating sinusoidal signal. If a ' $n$ ' level inverter is used, it will require 'n-1 ' carriers. Each carrier is compared to the modulating signal at each instant. If the modulating signal is greater than the triangular carrier, each comparison gives one, and zero otherwise. The results are added to give the level of voltage required at the inverter's output terminal. Frequency modulation ratio is defined as carrier frequency ratio and frequency modulation ratio.
Mf
$=$
$\mathrm{fc} /$

fm

Amplitude modulation ratio is defined as the ratio of amplitude of modulating signal and amplitude of carrier signal.

$\mathrm{Ma} \quad=\mathrm{Am} /(\mathrm{n}-$

1)Ac

The THD value can be reduced using this technique. THD is known as Total Harmonic Distortion and measures the level of distortion

The Multi Carrier PWM has seven carrier signals and one reference signal. The reference signal magnitude is maximum $5 \mathrm{~V}$ because five positive levels are required.In the motor side, we compare the actual voltage and the reference voltage. Reference voltage given here is $230 \mathrm{~V}$. Actual voltage is the output voltage obtained from the motor. Both are compared and the error is given to the carrier signal. Thus if there is any error the magnitude of the reference voltage will increase

PI is necessary because of thefollowing reasons. Two types of EMFsare produced, dynamically induced and statically induced EMF. According to Lenz Law, induced emf will oppose the direction of supply voltage. Hence, statically induced EMF is a problem. Therefore, we move to PI controllers. Drawbacks pertaining to PI controller is that the $\mathrm{Kp}$ and $\mathrm{Ki}$ values have to be added manually by trial and error method. It has no memory

\section{ARTIFICIAL NEURAL NETWORKS\& RESULTS}

Artificial Neural Network(ANN) imitate structure of the human brain, consisting of simple units that are known as arithmetic units which are connected to complex architectural layer. They can represent higher functions that are nonlinear in nature and carry out mapping with multi-input and multi-output. Using examples, they understand these processes or functions that are non linear. Innumerable types of artificial neural networks are currently being applied. One of these is the Multilayered Perception network abbreviated as MLP network. It is possibly the best and most researched upon and it is applied in many projects and techniques. These networks can perform almost any computation that is linear or non-linear and any reasonable functionality can be approximated. When presented with inputs they have never seen, properly trained networks tend to give reasonable answers. Whenever a newer input is given it will usually 
result in an output which is mostly similar to the correct output for the given input vectors similar to the new input presented used in training. This generalization property enables to train a network on a representative set of input / target pairs and get positive results on all feasible input / output combinations without training the network. The steps for optimum calculation of multilevel inverters' switching angles is done using ANN. The ANN block (Function fitting neural block is connected to the voltage output. It forms a closed loop that efficiently removes the harmonics in PWM Inverters

ANN has three layers: Input, Hidden and Output. It has a memory unlike PI. If any error is present after comparison, the hidden layer (memory) will be produced. If an error is stored in the memory, then again the reference and actual PWM signal will be compared, and the process repeats if another error is produced in hidden layer 2 . Now we check hidden layer 1 and 2. If the difference is zero, same reference signal will be compared with the carrier signal. If any difference is noticed, another hidden layer is produced and again it will compare and this process will continue four times. Hence, accuracy of the project increases. The simulation of the proposed closed loop inverter drive system powered by solar panels is shown in Fig .7. and closed loopisenhancedinFig. 8

\section{SIMULATION}
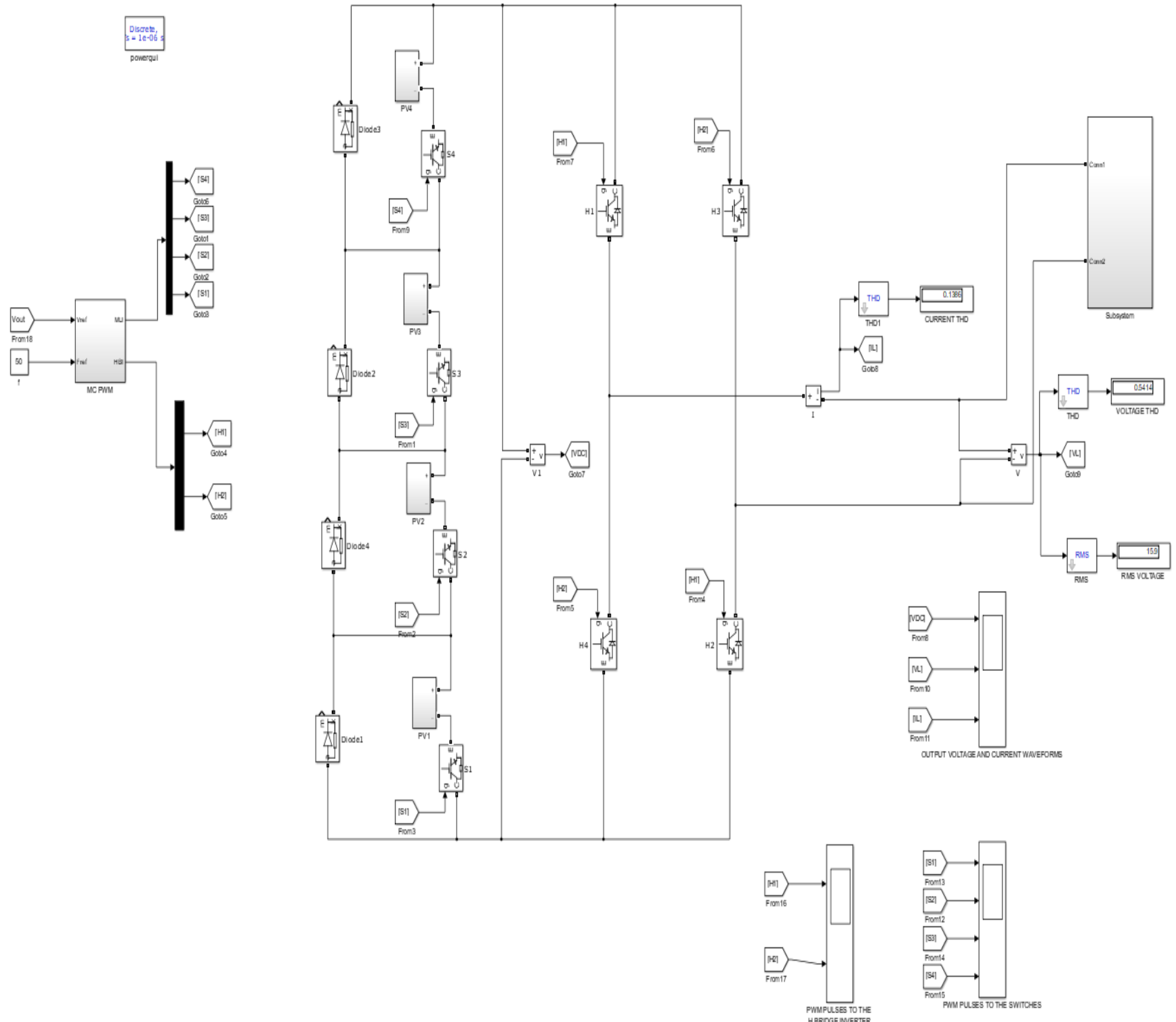

Fig.7.Simulation Of electric boat propulsion system (closed loop) 

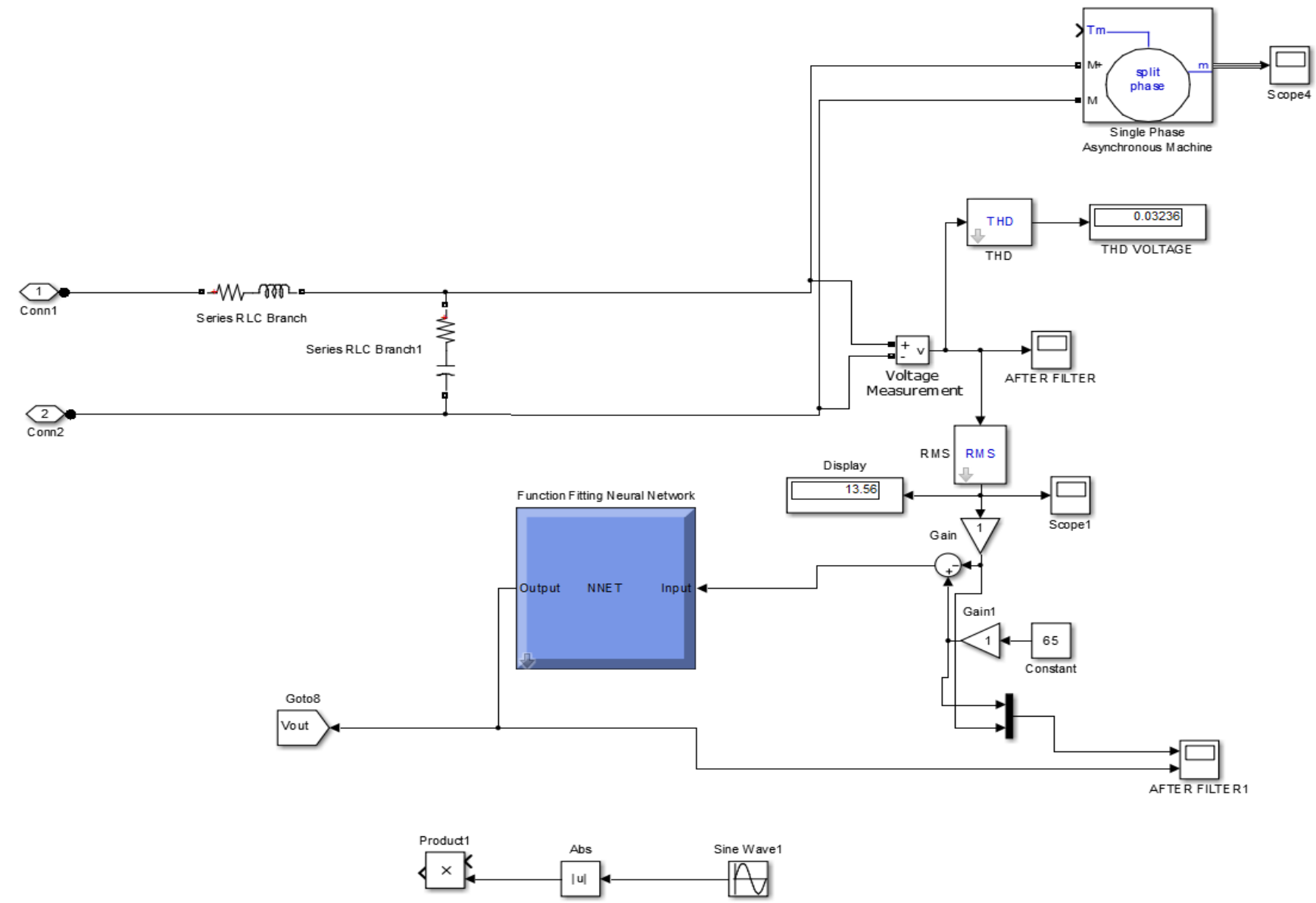

Fig.8.Closed loop connected to motor with ANN(subsystem)

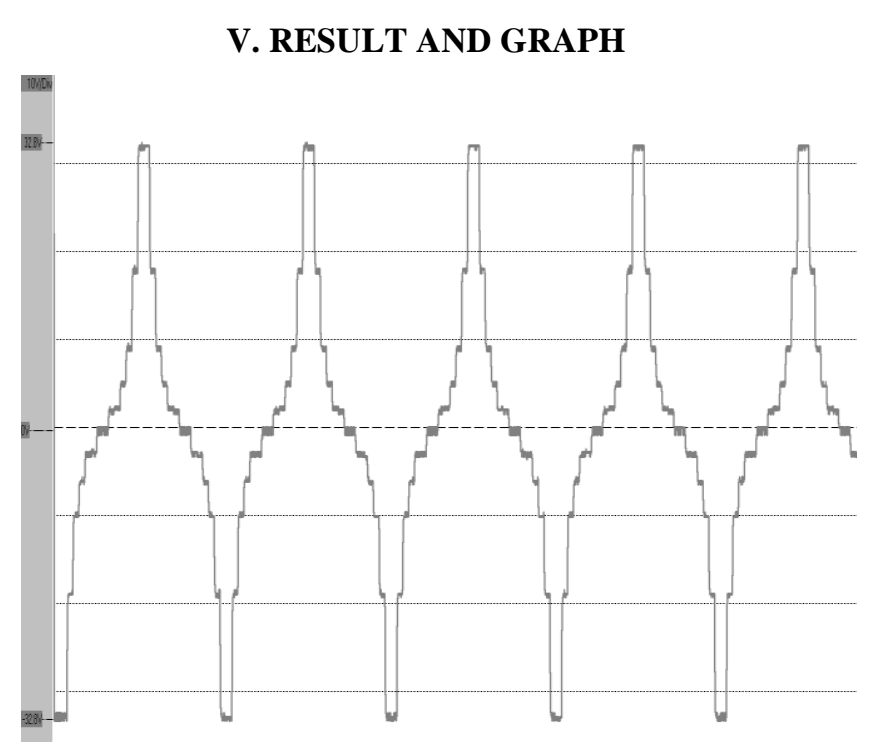

Fig.9.Eleven Level Hardware Output from DSO(Voltage vs time)

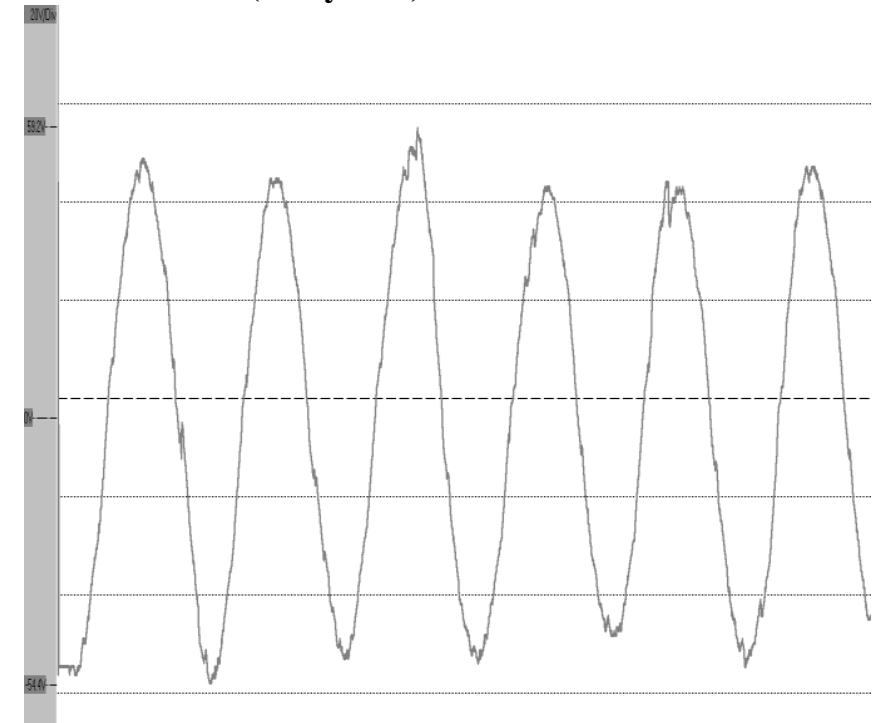

Fig.10.Sinusoidal Hardware Output after filter (Voltage vs time)

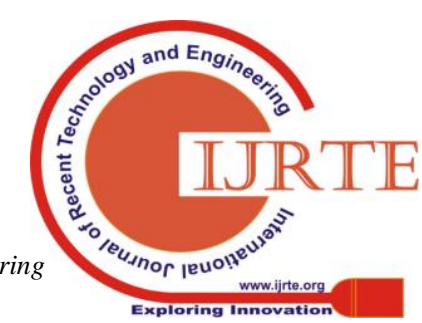



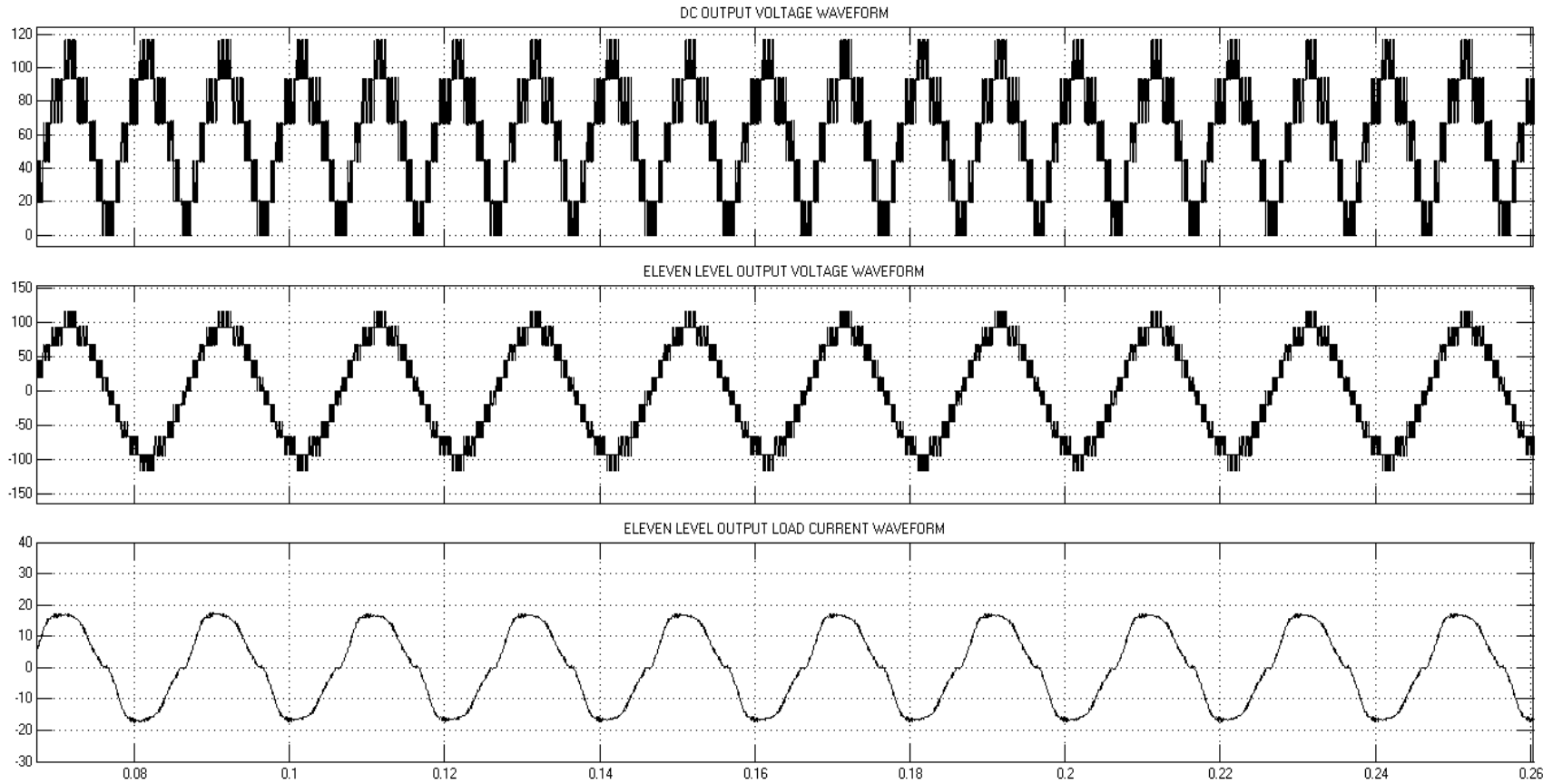

Time offset: 0

Fig.11. Eleven level output before filter, voltage vs time (matlab Simulink)

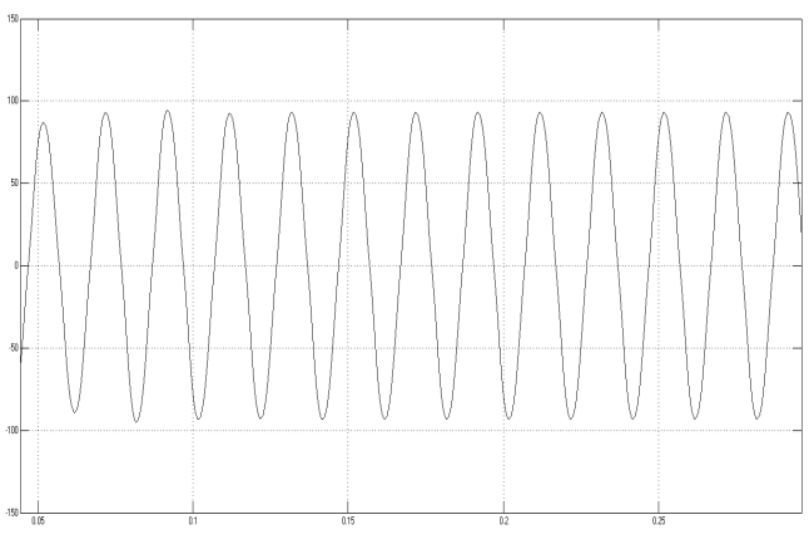

Fig.12.Eleven level output after filter, voltage vs time (matlab Simulink)

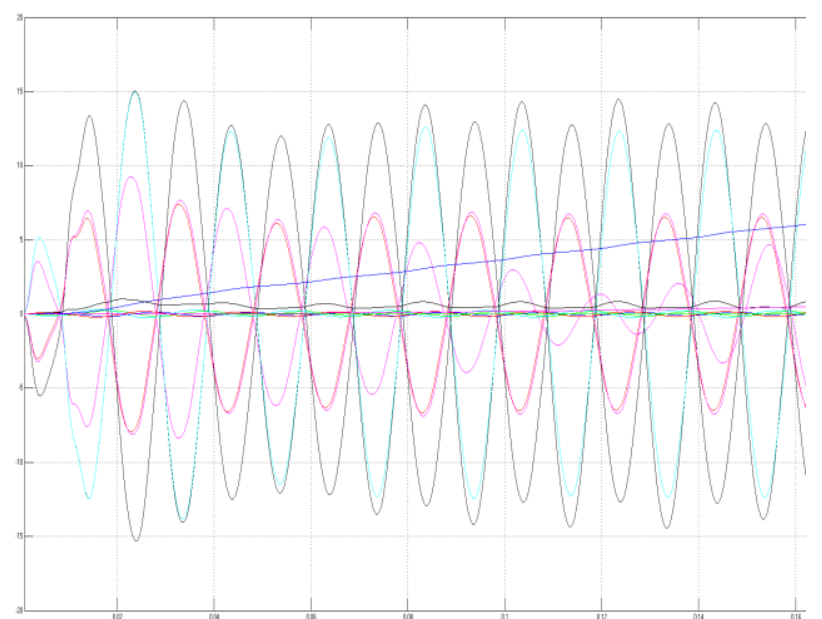

Fig.13.Motor Output showing various Current,Voltage, THD, Torque waveforms(w.r.t time)

Fig.9 shows the eleven level output of hardware system which is filtered to form a sinusoidal waveform as shown in Fig.10. Fig.11 shows output current and voltage waveform which is superior to the hardware due to closed loop incorporated in the system.Fig.12 shows the filtered sinusoidal output voltage with very few losses. The sinusoidal output voltage is then fed to the asynchronous split phase motor which runs the motor and gives functional waveforms as shown in Fig.13.

\section{CONCLUSION}

An all-electric propulsion system has been presented for boats that are used for public transportation. The main feature of this system include the use of the Eleven level inverter with closed loop controller to increase the efficiency of the system as well as the tapping of electricity for transportation. Among the converters presented is the use of power-converter topologies, which shows improved performance in terms of current sharing between power semiconductors and the volume of passive components. The ANN further removes harmonics to provide a smooth sinusoidal output voltage that is used to power the motor. This shows improved efficiency, performance, harmonic waveform, heat distribution and increased input and output frequency of the motor content because of the eleven leveloutput voltage and reduction of total harmonic distortion due to Artificial Neural Networks

\section{REFERENCES}

1. Abdullah Abdulslam, Baker Mohammad, Mohammed Ismail, Patrick P. Mercier, and Yehea Ismail, “A 93\% Peak Efficiency Fully-Integrated Multilevel Multistate Hybrid DC-DC Converter." IEEE Transactions on Circuits and Systems I:, vol.65, 2018

2. Cícero S. Postiglione ; Daniel A. F. Collier ; Bruno S Dupczak ; Marcelo L. Heldwein ; Arnaldo J. Perin, "Propulsion system for an all electric passenger boat employing permanent magnet synchronous motors and modern power electronics" 2012 Electrical Systems for Aircraft, Railway and Ship Propulsion ,Year: 2012 


\section{ELECTRIC BOAT PROPULSION SYSTEM USING MULTILEVEL CONVERTER BASED ON ANN CONTROLLER}

3. J. Lee, G. Hatcher, L. Vandenberghe, and C.-K. K. Yang, "Evaluation of fully-integrated switching regulators for CMOS process technologies,' IEEE Trans. Very Large Scale Integr. (VLSI) Syst., vol. 15, no. 9, pp. 1017-1027, Sep. 2007.

4. Selvakumar, K., Palanisamy, R., Vijayakumar, K., “ Implementation of quasi Z-source 7 level inverter with reduced switches using PV system," Journal of Advanced Research in Dynamical and Control Systems, 10 (7), pp. 1152-1161, June 2018.

5. S. R. Sanders, E. Alon, H.-P. Le, M. D. Seeman, M. John, and V. W. Ng, "The road to fully integrated DC-DC conversion via the switched capacitor approach," IEEE Trans. Power Electron., vol. 28, no. 9, pp. 4146-4155, Sep. 2013.

6. V. Yousefzadeh, E. Alarcón, and D. Maksimovic, "Three-level buck converter for envelope tracking applications," IEEE Trans. Power Electron., vol. 21, no. 2, pp. 549-552, Mar. 2006.

7. Selvakumar, K., Palanisamy, Karthikeyan, D., Selvabharathi, D., Bagchi, A., Gupta, V., Sinha, S., "Simulation of wind energy conversion system for 3-phase 3-level neutral point clamped inverter," Journal of Advanced Research in Dynamical and Control Systems, 10 (10), pp. 1662-1672, 2018.

8. G. Villar and E. Alarcon, "Monolithic integration of a 3-level DCM operated low-floating-capacitor buck converter for DC-DC step-down donversion in standard CMOS," in Proc. IEEE Power Electron. Spec. Conf. (PESC), pp. 4229-4235, 2008.

9. W. Kim, D. Brooks, and G.-Y. Wei, "A fully-integrated 3-level DC-DC converter for nanosecond-scale DVFS," IEEE J. Solid-State Circuits, vol. 47, no. 1, pp. 206-219, Jan. 2012

10. Selvakumar, K., Palanisamy, R., Vijayakumar, K. Karthikeyan, D., Selvabharathi, D., Kubendran, V., "Hysteresis control 3-Level SI-NPC inverter with Wind energy system," International Journal of Power Electronics and Drive Systems, 8 (4), pp. 1764-1770, December 2017.

11. J. Rodriguez, J.-S. Lai, and F. Z. Peng, "Multilevel inverters: a survey of topologies, controls, and applications," IEEE Transactions on Industrial Electronics, vol. 49, no. 4, pp. 724-738, August 2002.

12. F.Z.Peng, W.Qian, D.Cao, "Recent advances in multilevel converter/inverter topologies and applications," IEEE International Conference in power electronics (IPEC), pp. 492-501, Sapporo, Japan, 21-24 June 2010.Protein Pept Sci, 4(4):253-260, 2003.

13. D. Flower. "Immunoinformatics: "Predicting immunogenicity in silico". Quantum distributor, 1st edition, 2007. 